\title{
Springtime zooplankton size structure over the continental shelf of the Bay of Biscay
}

\author{
P. Vandromme ${ }^{1,6}$, E. Nogueira ${ }^{2}$, M. Huret ${ }^{3}$, Á. Lopez-Urrutia ${ }^{2}$, G. González-Nuevo González ${ }^{4}$, M. Sourisseau ${ }^{1}$, and \\ P. Petitgas ${ }^{5}$ \\ ${ }^{1}$ IFREMER, Centre Bretagne, Département Dynamique de l'Environnement Côtier, B.P. 70, 29280 Plouzané, France \\ ${ }^{2}$ Centro Oceanográfico de Gijón, Instituto Español de Oceanografía, Gijón 33212, Spain \\ ${ }^{3}$ IFREMER, Centre Bretagne, Unit. Sciences et Techniques Halieutiques, B.P. 70, 29280 Plouzané, France \\ ${ }^{4}$ Centro Oceanográfico de Vigo, Instituto Español de Oceanografía, Vigo 36200, Spain \\ ${ }^{5}$ IFREMER, Centre Nantes, Département Écologie et Modèles pour l'Halieutique, rue de l'Île d'Yeu, 44300 Nantes, France \\ ${ }^{6}$ GEOMAR, Helmholtz-Center for Ocean Science, Düsternbrooker Weg 20, 24105 Kiel, Germany
}

Correspondence to: P. Vandromme (pvandromme@geomar.de) and M. Huret (mhuret@ifremer.fr)

Received: 12 November 2013 - Published in Ocean Sci. Discuss.: 29 November 2013

Revised: 31 July 2014 - Accepted: 12 September 2014 - Published: 16 October 2014

\begin{abstract}
Linking lower and higher trophic levels requires special focus on the essential role played by mid-trophic levels, i.e., the zooplankton. One of the most relevant pieces of information regarding zooplankton in terms of flux of energy lies in its size structure. In this study, an extensive data set of size measurements is presented, covering parts of the western European continental shelf and slope, from the Galician coast to the Ushant front, during the springs from 2005 to 2012. Zooplankton size spectra were estimated using measurements carried out in situ with the Laser Optical Plankton Counter (LOPC) and with an image analysis of WP2 net samples $(200 \mu \mathrm{m}$ mesh size) performed following the ZooScan methodology. The LOPC counts and sizes particles within 100-2000 $\mu \mathrm{m}$ of spherical equivalent diameter (ESD), whereas the WP2/ZooScan allows for counting, sizing and identification of zooplankton from $\sim 400 \mu \mathrm{m}$ ESD. The difference between the LOPC (all particles) and the WP2/ZooScan (zooplankton only) was assumed to provide the size distribution of non-living particles, whose descriptors were related to a set of explanatory variables (including physical, biological and geographic descriptors). A statistical correction based on these explanatory variables was further applied to the LOPC size distribution in order to remove the non-living particles part, and therefore estimate the size distribution of zooplankton. This extensive data set provides relevant information about the zooplankton size distribution variability, productivity and trophic transfer efficiency in the
\end{abstract}

pelagic ecosystem of the Bay of Biscay at a regional and interannual scale.

\section{Introduction}

Size of the zooplankton can play an essential role in pelagic ecosystems (Stemmann and Boss, 2012). Physiological rates as well as predator-prey interactions of zooplankton are thought to be size-dependent (Peters and Wassenberg, 1983; Barnes et al., 2011; Bachiller and Irigoien, 2013). Therefore, the zooplankton size structure has been used as a key ecological indicator of the dynamics of zooplankton communities (Sheldon et al., 1972; Krupica et al., 2012) and is considered and resolved nowadays in an increasing number of ecosystem models (e.g., Baird and Suthers, 2007; Ward et al., 2012). In particular, the size-based approach becomes appropriate in trophodynamic observation or modeling studies linking lower and upper trophic levels (Daewel et al., 2014); i.e., looking at potential top-down control on zooplankton, or estimating food availability to fish (e.g., Bachiller and Irigoien, 2013). For the latter case, the size of prey field is indeed a key model component, especially for fish larvae (e.g., anchovy and sardine, Poulet et al., 1996; Morote et al., 2010). For instance, Daewel et al. (2008) proposed the sorting of modeled zooplankton biomass in size classes according to the average 
slope of in situ zooplankton size spectra in order to improve model realism. In relation to end-to-end fish models, observations of the size-structure of zooplankton are thus needed to provide the prey field, to calibrate the size-structured component of the model and to simplify model structure.

However, measuring the size distribution of the zooplankton is not straightforward; various instruments exist, each of them having pros and cons. The size structure of the zooplankton can be measured in situ by particle counters such as the (Laser) Optical Plankton Counter (OPC and LOPC, Herman et al., 2004) that measures the size of all particles, in the range from $100 \mu \mathrm{m}$ to a few millimeters equivalent spherical diameter (ESD), crossing a light of laser field. However, the discrimination between living and nonliving particles with these instruments is not possible, although using derived parameters, such as transparency, allows some discrimination (e.g., particles $>2 \mathrm{~mm}$ measured by the LOPC; Checkley et al., 2008). Recently, Petrik et al. (2013) proposed a way of discriminating living and nonliving particles smaller than $2 \mathrm{~mm}$ counted by the LOPC by fitting a log-normal curve to the biovolume spectrum; residuals are considered to be living particles. Another way of measuring the zooplankton size structure is through traditional net samples followed by manual or automated counting and sizing (Bachiller et al., 2012; Vandromme et al., 2012). Even though this procedure allows a higher taxonomic resolution, the large amount of time required generally prevents its widespread use. Another approach to measuring the zooplankton size-structure is through in situ imaging systems (e.g., Picheral et al., 2010), although the instruments designed for that purpose are still relatively recent and not yet widely used and fully validated against traditional methods. In any case, in situ imaging and traditional methods allow counting and sizing particles, and hence the construction of abundance (or biovolume) size spectra in a given size range. In our case, the LOPC allows the quantitative measurement of particles between 100 and $\sim 2000 \mu \mathrm{m}$ ESD, while the ZooScan analysis on samples from WP2 net of $200 \mu \mathrm{m}$ mesh-size covers the size range from 400 to $\sim 2500 \mu \mathrm{m}$ ESD (Nichols and Thompson, 1991; Vandromme et al., 2012). The comparison between abundance estimates derived from different sampling approaches renders contrasting results. Total counts from net catches are generally lower than or equal to those observed by in situ particle counters (González-Quirós and Checkley, 2006; Schultes and Lopes, 2009; Gaardsted et al., 2010), and this difference was attributed mainly to fragile aggregates and detritus that are often not analyzed in net catches but also disaggregated by the net passage and thus not correctly sampled (e.g., GonzálezQuirós and Checkley, 2006). Fragile gelatinous zooplankton can also be destroyed by passage through the net and may also partially account for the difference between in situ particles counters and net catches. Different optical sensors can provide discrepant abundance estimates. For instances, Basedow et al. (2013) showed that a video plankton recorder
(VPR) yielded twice as high an abundance of Calanus finmarchicus than a LOPC, which in turn yielded abundances of the same order of magnitude than those from samples acquired with a Multinet and enumerated under a stereomicroscope.

Few studies have provided zooplankton biomass distribution or size structure at regional scale of the continental shelf of the Bay of Biscay. Poulet et al. (1996) reviewed zooplankton size information from locations rather irregularly distributed along the Bay of Biscay; Valdés et al. (2007) and Albaina and Irigoien (2004) from long time series of local transects in the north of Spain or in front of the Gironde estuary, respectively; Nogueira et al. (2004) and Sourisseau and Carlotti (2006) from biomass and size structure of the mesozooplankton measured by an optical plankton counter from a single season and 2 years, respectively; or from a time series of biomass and size-spectrum maps over the southern French shelf of the bay over a decade in spring (Irigoien et al., 2009).

Regarding differences between size spectra measured by the LOPC (which accounts for both living and non-living particles) and by traditional WP2 net samples analyzed by ZooScan (which considers only zooplankton; named WP2/Zs approach through the text), a statistical correction based on correlations between the differences observed and environmental data is proposed in this study, in order to estimate the zooplankton size spectra where WP2/Zs data are missing. Estimated zooplankton size spectra are further investigated to depict correlations between total zooplankton biomass and the shape of the size distribution. This allows the large available data set from surveys made with the LOPC to be used for the characterization of the size structure patterns of the zooplankton in the Bay of Biscay. Estimated zooplankton size spectra are further investigated to depict correlations between total zooplankton biomass and the shape of the size distribution. Following this methodological approximation, the spatial and interannual variability of the habitats defined by the size spectra distribution are discussed in terms of energy transfer to upper trophic levels, from ecological and modeling perspectives.

\section{Materials and methods}

\subsection{Zooplankton sampling}

Samples were collected in the Bay of Biscay (Fig. 1) onboard R/V Thalassa during PELGAS and PELACUS cruises, respectively, the French and Spanish acoustic surveys for stock assessment of small pelagic fishes, which were annually carried out in spring. Both PELGAS and PELACUS cruises are part of the Data Collection Framework (DCF) of the European Commission. Collected data are shared within the Working Group on Horse Aackerel, Sardine and Anchovy (WGHMSA) and the Working Group on Accoustics and 


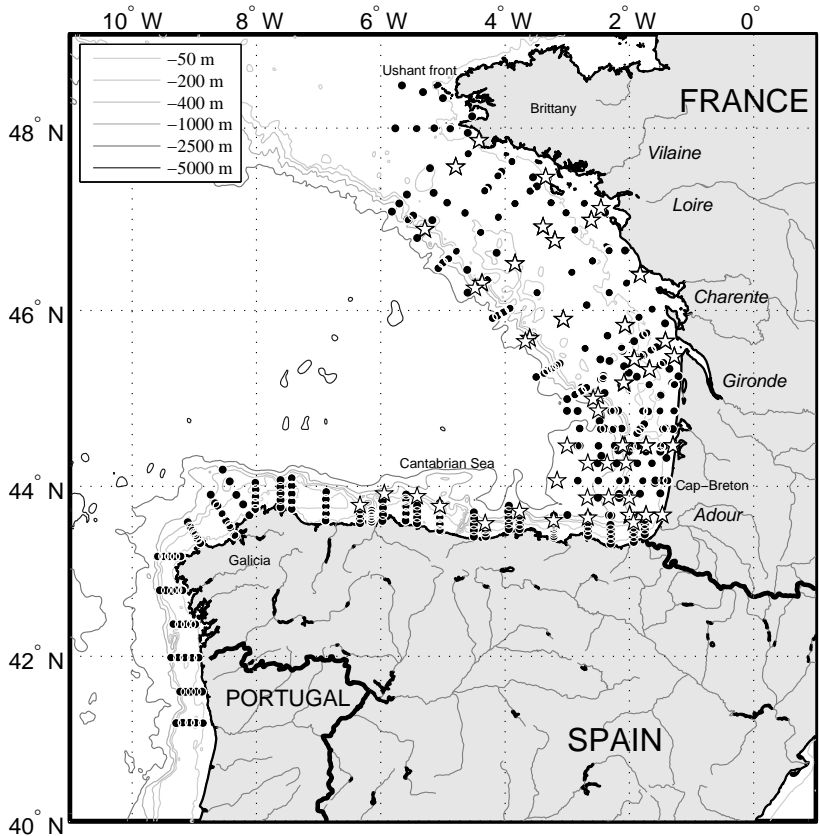

Figure 1. Map of the Bay of Biscay showing the location of stations (black circle for LOPC/CTD only and white star for LOPC/CTD and WP2 net).

Eggs (WGACEGG) of the International Council for the Exploration of the Sea (ICES/CIEM). Supplementary information on PELGAS cruises can be found in Doray et al. (2014). At each station during the night, a structure containing a CTD probe (seabird SBE19) and several automatic sensors including a LOPC were lowered from the surface down to the bottom of the water column (to a maximum depth of $600 \mathrm{~m}$ ) at $1 \mathrm{~m} \mathrm{~s}^{-1}$. At some stations, a vertical haul with a WP2 net (without a flow meter) was conducted down to $100 \mathrm{~m}$ depth (or to $2 \mathrm{~m}$ above the bottom in shallower stations). Data from the CTD probe as well as nutrients and chlorophyll $a$ are available online through the SEADATANET portal (www.seadatanet.org).

The total numbers of stations with LOPC and/or WP2/Zs data are presented in Table 1. The French PELGAS survey followed directly after the Spanish PELACUS survey aboard the same vessel, both operating similar CTD, LOPC and WP2 net tows. A span of $\sim 2$ months separate the start of the survey in the south from the end in the north of the Bay. The distance between stations are approximately $24 \mathrm{~nm}$ $(\sim 44 \mathrm{~km})$ in the alongshore direction, and 10 to $25 \mathrm{~nm}(\sim 19$ to $46 \mathrm{~km}$ ) in the cross-shelf direction which shows strongest gradients, with refinement for the latter in the known frontal areas and over the Iberian shelf.

This sampling strategy prevents any assessment of observed variability at short temporal (Sourisseau and Carlotti, 2006) and spatial scale, yet, interpretation may be affected by population dynamic patterns or patchiness. However, as noticed by Sourisseau and Carlotti (2006), the spatial variability
Table 1. Number of stations with LOPC and/or WP2/Zs data per cruises. There is a total of 816 LOPC profiles and 89 WP2 net samples analyzed with the ZooScan. The table also shows the start and end dates of the cruises.

\begin{tabular}{lllrr}
\hline Cruise & First station & Last station & \#LOPC & \#WP2/Zs \\
\hline PELACUS 2005 & 5 Apr & 29 Apr & 100 & 0 \\
PELGAS 2005 & 5 May & 30 May & 52 & 0 \\
PELACUS 2006 & 3 Apr & 18 Apr & 43 & 0 \\
PELACUS 2007 & 11 Apr & 21 Apr & 55 & 14 \\
PELGAS 2007 & $27 \mathrm{Apr}$ & 18 May & 55 & 0 \\
PELACUS 2009 & 2 Apr & 20 Apr & 77 & 0 \\
PELGAS 2009 & 26 Apr & 2 Jun & 105 & 24 \\
PELGAS 2010 & 26 Apr & 2 Jun & 117 & 23 \\
PELGAS 2011 & 29 Apr & 3 Jun & 127 & 29 \\
PELGAS 2012 & 27 Apr & 24 May & 85 & 0 \\
\hline
\end{tabular}

at our sampling scale is higher than the temporal variability, giving confidence to our results. Based on the analysis of Albaina and Irigoien (2004), a minimum resolution of $12 \mathrm{~nm}$ $(\sim 22 \mathrm{~km})$ is necessary in the cross-shelf direction to obtain realistic patterns of mesozooplankton distribution in frontal areas, therefore, our sampling should allow identification of major spatial patterns of size distribution and habitat at the mesoscale.

\subsection{Measurement of the size distribution}

\subsubsection{Laser-Optical Plankton Counter (LOPC)}

The Laser Optical Plankton Counter (Herman et al., 2004), is an optical instrument capable of measuring in situ the size of particles by crossing a laser beam. The smallest recorded objects are of $\sim 100 \mu \mathrm{m}$ ESD and the largest are of a few millimeters to centimeters. SEPs are Single Element Particles and MEPs are Multiple Element Particles, which means that MEPs activate more than one diode when crossing the laser field of the LOPC. In the present work, the analysis is limited to sizes below $1.9 \mathrm{~mm}$ ESD, which corresponds to the maximum measurable size of SEPs (MEPs lower than $1.9 \mathrm{~mm}$ ESD were added to the size distribution). Problems of coincidence in case of high particle concentrations that often arise with the OPC (Woodd-Walker et al., 2000) are largely decreased with the LOPC (Herman et al., 2004). The LOPC is mounted on the CTD-Rosette, has a sampling window of $49 \mathrm{~cm}^{2}$, and samples the water column at a rate of $2 \mathrm{~Hz}$ with a lowering speed of $\sim 0.5 \mathrm{~m} \mathrm{~s}^{-1}$ (values recorded at a speed $<0.2 \mathrm{~m} \mathrm{~s}^{-1}$ were removed from analysis).

\subsubsection{WP2 net samples and in lab imaging analysis (WP2/Zs)}

Zooplankton sampling was done at night by vertical tows (maximum $100 \mathrm{~m}$ depth or to $2 \mathrm{~m}$ above the surface) with a WP2 net (mesh size of $200 \mu \mathrm{m}$, mouth area of $0.25 \mathrm{~m}^{2}$ ). The WP2 quantitatively samples objects from $\sim 400$ through 
$\sim 2500 \mu \mathrm{m}$ ESD (Nichols and Thompson, 1991; Vandromme et al., 2012). Since no flow meter was mounted on nets, the sampled volume was simply calculated as the towed length times the mouth area of the net. This also prevented any estimate of net clogging that could potentially occur in eutrophic coastal areas. The WP2 net filtering : mouth areas ratio, adjusted to porosity, is about 6 (Hernroth, 1987; Keen, 2013), which is above the recommended ratio for coastal (or green) waters of 3.9 (calculated with a sampled volume of $25 \mathrm{~m}^{3}$, equivalent to a $100 \mathrm{~m}$ vertical tow Smith et al., 1968).

A selection of available WP2 samples representative of different locations of the sampled area were processed with the ZooScan/ZooProcess system, a laboratory flatbed scanning system used for the digitization of fixed wet net samples (Gorsky et al., 2010). The ZooScan used here had a scanning surface of $15 \times 24 \mathrm{~cm}$ and a pixel width of $10.56 \mu \mathrm{m}$ ( $2400 \mathrm{dpi} ; 14200 \times 22700$ pixels). For each sample, small and large objects were first separated in two size fractions with a mesh of $1000 \mu \mathrm{m}$, and further subsampled with a Motoda box. Each subsample was scanned after a manual separation of objects on the scanning tray to reduce the occurrences of touching objects (Vandromme et al., 2012). All objects were then visually classified into zooplankton or non-living particles. Furthermore, zooplankton only from the PELGAS cruises were sorted into a total of 18 categories consisting of 8 copepods groups (Acartia sp., Calanus sp., Centropages sp., Temora sp., Oithona sp., other calanoids larger and smaller than $1 \mathrm{~mm}$ ESD, and other copepods), cladocerans, other large crustaceans (mostly euphausiids, gamariids, mysiids and decapods larvae), other small crustaceans (mostly nauplii and cirripods), chaetognaths, $\mathrm{Li}$ macina sp., other molluscs, carnivorous gelatinous, appendicularians, thaliaceans and other zooplankton.

\subsubsection{Size spectra calculation}

The size spectra are expressed as normalized biomass size spectra (NBSS) according to Platt and Denman (1977) and Blanco et al. (1994), in other words

$\beta(w)=\frac{B(w)}{\Delta(w)}$,

where $w$ is the carbon weight for a given size class, $\beta(w)$ is the normalized form, $B(w)$ is the un-normalized form and $\Delta(w)$ is the width of each size class. The carbon weight is calculated from the ESD of each object (both for the LOPC and the WP2/Zs) following ESD-to-dry weight (Lehette and Hernández-León, 2009) and dry weight-to-carbon (Mauchline, 1998) conversion equations:

$$
\begin{aligned}
& \mathrm{ar}=\pi(\mathrm{ESD} / 2)^{2} \\
& \mathrm{dw}=43.38 \mathrm{ar}^{1.54} \\
& w=0.447 \mathrm{dw}
\end{aligned}
$$

where ar is the projected 2-D area of the object (in $\mathrm{mm}^{2}$ ), $\mathrm{dw}$ is the dry weight (in $\mu \mathrm{g}$ ) and $w$ is in $\mu \mathrm{gC}$. Size spectra were described by the slope $s$ and intercept $a$ of a log-linear regression (Blanco et al., 1994). Although some correlations exist between slopes and intercepts, both are needed to efficiently describe the NBSS (Gómez-Canchong et al., 2013). Non-linearity of size spectra is a common observed feature (Nogueira et al., 2004; Sourisseau and Carlotti, 2006) and reflects a non-equilibrium state as compared to theoretical models (Kerr and Dickie, 2001). However, the present work focuses on the principal scaling of the ecosystem structure (zooplankton size spectrum and its spatial variability, Kerr and Dickie, 2001), which is physiological (primary scaling) and ecological (secondary scaling), rather than on short term population dynamics, one of the factors leading to these nonlinearities.

\subsection{Environmental data set}

Hydrological parameters were measured simultaneously with LOPC records. Values of temperature, salinity and density at surface and bottom were used (surface $\sim 4 \mathrm{~m}$ depth, bottom corresponds to $100 \mathrm{~m}$ or less, depending on the bathymetry). The total fluorescence integrated from surface to bottom, the depth of the maximal fluorescence and the value of fluorescence at its maximum were also included. Fluorescence data were calibrated each year against in situ measurements of chlorophyll $a$. The stratification (first differences) was computed from density and the mean and maximum values were used. The mixed layer depth was also included, calculated by a finite difference criteria $\left(0.02 \mathrm{~kg} \mathrm{~m}^{-2}\right.$ higher than the surface, $4 \mathrm{~m}$ depth, value, Kara et al., 2000). In addition, daily satellite data of chlorophyll $a$ and inorganic suspended particulate matter (SPM), processed with a specific algorithm for Case 2 coastal waters (Gohin et al., 2005), at the sampling date as well as 7 and 14 days before were included. Finally, bathymetry, distance to the coast, latitude and Julian day were also included. This formed a data set of 22 environmental explanatory variables. Integrated and maximum fluorescence, satellite chlorophyll $a$ and suspended matter as well as bathymetry were log transformed. At 68 stations (PELGAS 2009, 2010 and 2011), the surface chlorophyll $a$ was measured for three size fractions, i.e., below $3 \mu \mathrm{m}$, from 3 to $20 \mu \mathrm{m}$ and above $20 \mu \mathrm{m}$.

\subsection{Zooplankton size distribution analysis}

LOPC size spectra were averaged over the same depth intervals as those size spectra derived from the WP2/Zs approach. LOPC and WP2/Zs have comparable size ranging from $\sim 400$ to $2000 \mu \mathrm{m}$ ESD. The difference between the WP2/Zs NBSS and the LOPC NBSS within this size range was assumed to give the size distribution of non-living particles. Over this difference, a log-linear regression was performed, and its slope $\left(a_{\mathrm{nl}}\right)$ and intercept $\left(b_{\mathrm{nl}}\right)$ were considered as the descriptors of the non-living (nl) particles size distribution. 
A stepwise redundancy analysis (Stepwise RDA Legendre and Legendre, 2012, Chap. 11.1) was first performed to assess the variance of the non-living particle size distribution. The stepwise RDA was performed on a table of response variables $\mathbf{X}$, which corresponded to $a_{\mathrm{nl}}$ and $b_{\mathrm{nl}}$, explained by a table $\mathbf{Y}$ of explanatory variables, which included the set of environmental variables together with the NBSS LOPCderived biomass (in $\log _{10}$ ) and slope. The stepwise RDA was also performed on reduced $\mathbf{Y}$ tables including variables not available for all stations (e.g., fractionated chlorophyll $a$ ).

Then, in order to compute the coefficients of the multiple regression to be applied on the explanatory variables to estimate $a_{\mathrm{nl}}$ and $b_{\mathrm{nl}}$, a partial least square regression was used (PLS regression; de Jong, 1993; Rosipal et al., 2006). The robustness of the PLS regression was assessed by performing a total of 5000 permutations with a random removal of 4 stations for each permutation. Average PLS regression coefficients were then applied on the whole LOPC size spectra to estimate the zooplankton size distribution for each station of each year occurring in the data set.

The methodology of Petrik et al. (2013) was also implemented in the analysis. The LOPC size spectra were converted into volumes, and a log-normal distribution representing the non-living particles was estimated. This distribution was then subtracted from LOPC counts to estimate the distribution of the zooplankton.

Further, the zooplankton growth as a function of water temperature, chlorophyll $a$ and weight of individuals (in mgC) was calculated (Huntley and Boyd, 1984; Hirst and Bunker, 2003; Zhou et al., 2010); the production is the growth rate multiplied by the total biomass of zooplankton; the total biomass was calculated as the integral of an assumed linear NBSS:

$$
\begin{aligned}
& B=\int_{x_{\min }}^{x_{\max }} a x^{s} \mathrm{~d} x, \\
& B=\frac{a x_{\max }^{s+1}}{s+1}-\frac{a x_{\min }^{s+1}}{s+1},
\end{aligned}
$$

where $B$ is the biomass between $x_{\min }$ and $x_{\max }, s$ is the slope and $a$ the intercept of the NBSS. $x_{\min }$ and $x_{\max }$ correspond to 200 and $2000 \mu \mathrm{m}$ ESD, respectively, covering the size range of mesozooplankton. The production was summed from the surface to a max of $100 \mathrm{~m}$ depth to have an estimated productivity per square meter.

Maps of estimated zooplankton biomass, slopes and productivity were computed for each year on a $50 \times 50$ grid ( $\sim 20 \times 20 \mathrm{~km}$ cells) covering the whole Bay of Biscay. Average maps were then generated from the means of each annual map. The interannual and spatial variability of zooplankton NBSS were analyzed through the distribution of five groups that were calculated by $K$ means clustering computed on normalized values of slopes and log-transformed biomass. The number of groups was arbitrarily chosen to produce the best trade-off between the level of details needed to detect patterns and readability.

All analyses were performed with Matlab R2012a with the use of the Fathom toolbox for the Stepwise RDA (David L. Jones, www.marine.usf.edu/user/djones).

\section{Results}

\subsection{Size distribution of non-living particles}

The LOPC size spectra showed slopes ranging from -1.73 to 0.40 with a mean ( \pm standard deviation) of $-0.97 \pm 0.24$. Intercepts ranged from -1.88 to 5.15 with a mean of $1.76 \pm$ 1.39. The coefficients of determination against the linear regression showed a mean of $0.95 \pm 0.03$ which highlights the high linearity of the size distribution. WP2/Zs size spectra showed slopes ranging from -2.08 to 0.10 with a mean of $-0.86 \pm 0.40$, and intercepts ranging from -2.36 to 2.54 with a mean of $0.15 \pm 1.20$. The coefficients of determination of WP2/Zs size spectra against the linear regression were $0.92 \pm 0.06$, slightly less than the LOPC size spectra. The LOPC and WP2/Zs slopes had a Pearson correlation coefficient of 0.57 and intercepts of 0.62 .

On Fig. 2, examples of LOPC and WP2/Zs size spectra measured at the same stations are presented. Differences between slope and intercepts of the size distribution of nonliving particles for all stations are shown in Fig. 3. For some cases in PELGAS 2009 and 2010, the slopes of the WP2/Zs were steeper than that of the LOPC (red colored); these cases were mainly located on coastal stations. Stations where both LOPC and WP2/Zs estimates are comparable (small white circles) are generally located offshore, in the middle of the continental shelf, or over the slope of the French shelf. During PELGAS 2011 (Fig. 3e), non-living particles seemed mainly located in the southern part of the French continental shelf. However, for most cases, no geographical patterns emerged.

Stepwise RDA results are shown in Table 2. The cumulative explained variance (Cum. Exp.) for all variables included reaches $73 \%$ of the total variance. Most of the variance was explained by the total biomass of particles estimated from LOPC (40\% of variance explained), followed by the chlorophyll $a$ measured by satellite at sampling time (52\% Cum. Exp.), the bathymetry (56\% Cum. Exp.) and the slopes of the size distribution of all particles measured with the LOPC (59\% Cum. Exp.). Since the variance explained by a variable was removed prior to the selection of the next variable, a variable strongly correlated with a previous extracted one is not likely to add much to the cumulated explained variance. The variance explained by each variable on the initial $\mathbf{X}$ matrix is shown in the column Tot. Expl. of Table 2. For example, the Julian day explained $12 \%$ of the initial X matrix, but appeared on the 9th position in the stepwise RDA. 
Table 2. Results of the stepwise redundancy analysis (RDA) and simple RDA performed on residuals from NBSSs of [LOPC-WP2/Zs]. Par. $\mathrm{F}=$ partial F statistic; Cum. Exp. = cumulative fraction of variance explained; Tot. Expl. = fraction of the total variance explained; Tot. $\mathrm{F}=$ total F statistic; $p=p$ values for significance of the F statistic; Sat. $=$ Satellite; surf. $=$ surface; bottom $=100 \mathrm{~m}$ depth or maximum depth of the profile; strat. $=$ stratification; $T^{\circ}=$ temperature; Sal. $=$ salinity; chla $=$ chlorophyll $a ;$ Fluo. $=$ fluorescence; Depth of fluo. max $=$ depth of the maximum value of fluorescence; $\mathrm{MLD}=$ mixed layer depth; SPM = suspended particulate matter; Int. = Integrated value from surface to bottom depth; $\max =$ maximum value observed between surface and bottom depth; d-7/14= Satellite data 7 and 14 days before the sampling date; Coast dist. = distance to the coast. The last column represents the sign of the correlation between the slope and the intercept of the residuals (i.e., the non-living matter), respectively; e.g., Sat. chla is positively correlated to the slopes but negatively to the intercepts.

\begin{tabular}{|c|c|c|c|c|c|c|c|}
\hline \multirow[b]{2}{*}{ Variables } & \multicolumn{3}{|c|}{ Stepwise RDA } & \multicolumn{3}{|c|}{ Simple RDA } & \\
\hline & Cum. Exp. & Par. F & $p$ & Tot. expl. & Tot. F & $p$ & \\
\hline LOPC biomass & 0.40 & 55.02 & 0.01 & 0.4 & 55.02 & 0.01 & ++ \\
\hline Sat. chla & 0.52 & 20.78 & 0.01 & 0.01 & 0.82 & 0.01 & +- \\
\hline Bathymetry & 0.56 & 7.68 & 0.01 & 0.02 & 1.29 & 0.01 & -- \\
\hline LOPC slope & 0.59 & 6.28 & 0.01 & 0.25 & 28.41 & 0.01 & +- \\
\hline Density bottom & 0.61 & 3.55 & 0.22 & 0.06 & 5.77 & 0.01 & -- \\
\hline$T^{\circ}$ bottom & 0.62 & 2.90 & 0.12 & 0.01 & 0.63 & 0.52 & -+ \\
\hline Salinity bottom & 0.66 & 7.89 & 0.01 & 0.03 & 2.85 & 0.01 & -- \\
\hline Sat. chla d-7 & 0.68 & 5.61 & 0.01 & 0.05 & 4.47 & 0.15 & ++ \\
\hline Julian day & 0.69 & 2.24 & 0.23 & 0.12 & 11.31 & 0.01 & +- \\
\hline Latitude & 0.70 & 1.94 & 0.22 & 0.09 & 8.64 & 0.01 & +- \\
\hline Sat. chla d-14 & 0.70 & 1.09 & 0.11 & 0.01 & 1.09 & 0.24 & ++ \\
\hline Sat. SPM d-7 & 0.70 & 0.84 & 0.47 & 0.01 & 0.43 & 0.48 & ++ \\
\hline Strat. mean & 0.71 & 1.32 & 0.21 & 0.02 & 1.96 & 0.35 & ++ \\
\hline Sat. SPM d-14 & 0.71 & 0.60 & 0.30 & 0.00 & 0.33 & 0.64 & ++ \\
\hline Depth of fluo. max & 0.71 & 0.30 & 0.76 & 0.01 & 1.11 & 0.29 & -- \\
\hline MLD & 0.71 & 0.15 & 0.6 & 0.03 & 2.61 & 0.01 & -- \\
\hline Coast dist. & 0.71 & 0.11 & 0.91 & 0.07 & 6.29 & 0.01 & -- \\
\hline Fluo. max & 0.71 & 0.07 & 0.81 & 0.00 & 0.32 & 0.75 & ++ \\
\hline Sat. SPM & 0.72 & 0.08 & 0.91 & 0.02 & 1.42 & 0.34 & ++ \\
\hline$T^{\circ}$ surf. & 0.72 & 0.04 & 1.00 & 0.02 & 2.04 & 0.30 & -- \\
\hline Strat. max & 0.72 & 0.05 & 0.91 & 0.07 & 5.88 & 0.01 & ++ \\
\hline Salinity surf. & 0.72 & 0.04 & 0.91 & 0.06 & 5.67 & 0.01 & -- \\
\hline Density surf. & 0.73 & 3.33 & 0.10 & 0.04 & 3.26 & 0.14 & +- \\
\hline Fluo. int. & 0.73 & 0.00 & 1.00 & 0.00 & 0.01 & 1.00 & -+ \\
\hline
\end{tabular}

Without LOPC-derived variables, the variance explained decreased to $47 \%$.

Table 3 shows the effect of including fractionated surface chlorophyll $a$ to the $\mathbf{Y}$ matrix. In this reduced $\mathbf{Y}$ matrix (68 stations), the total cumulated explained variance is $74 \%$ without fractionated chlorophyll $a$, but reaches $80 \%$ with its inclusion. However, the first four variables in Table 3 account for the same explained variance as the first four in Table 2. A last stepwise RDA was made using the 18 zooplankton categories (Table 4) available for 75 stations. The stepwise RDA with the same explanatory variables as above (Table 2) shows a total cumulated explained variance of $71 \%$, whereas with the 18 zooplankton categories the explained variance reaches $92 \%$. The first four zooplankton categories explains $82 \%$ of the variance (Acartia sp., cladocerans, Calanus sp. and other calanoids smaller than $1 \mathrm{~mm}$ length).

\subsection{Accuracy of estimated zooplankton size spectra}

The average explained variance by the PLS regression was $74.7 \pm 1.9 \%$, similar to the stepwise RDA. Correlations between WP2/Zs slopes and intercepts and the LOPC ones, before and after the subtraction of estimated non-living particles, are shown in Fig. 4 and in Taylor diagrams (Fig. 5, Taylor, 2001). The Pearson correlation between WP2/Zs slopes and intercepts with the ones of the LOPC are, respectively, $0.57(p<0.001)$ and $0.62(p<0.001)$. In the case of the intercepts (Fig. 4b), a strong overestimation by the LOPC was also observed (means are significantly different, Student $t$ test $p<0.001)$. After the subtraction, Pearson correlations reached 0.78 and 0.85 (both $p<0.001$ ) for slopes and intercepts, respectively. The overestimation of the intercept by the LOPC was also reduced with the PLS regression (no significant difference in means observed, Student $t$ test $p=0.39$ ). The Petrik et al. (2013) methodology gives Pearson correlations of $0.61(p<0.001)$ and $0.66(p<0.001)$ with WP2/Zs 

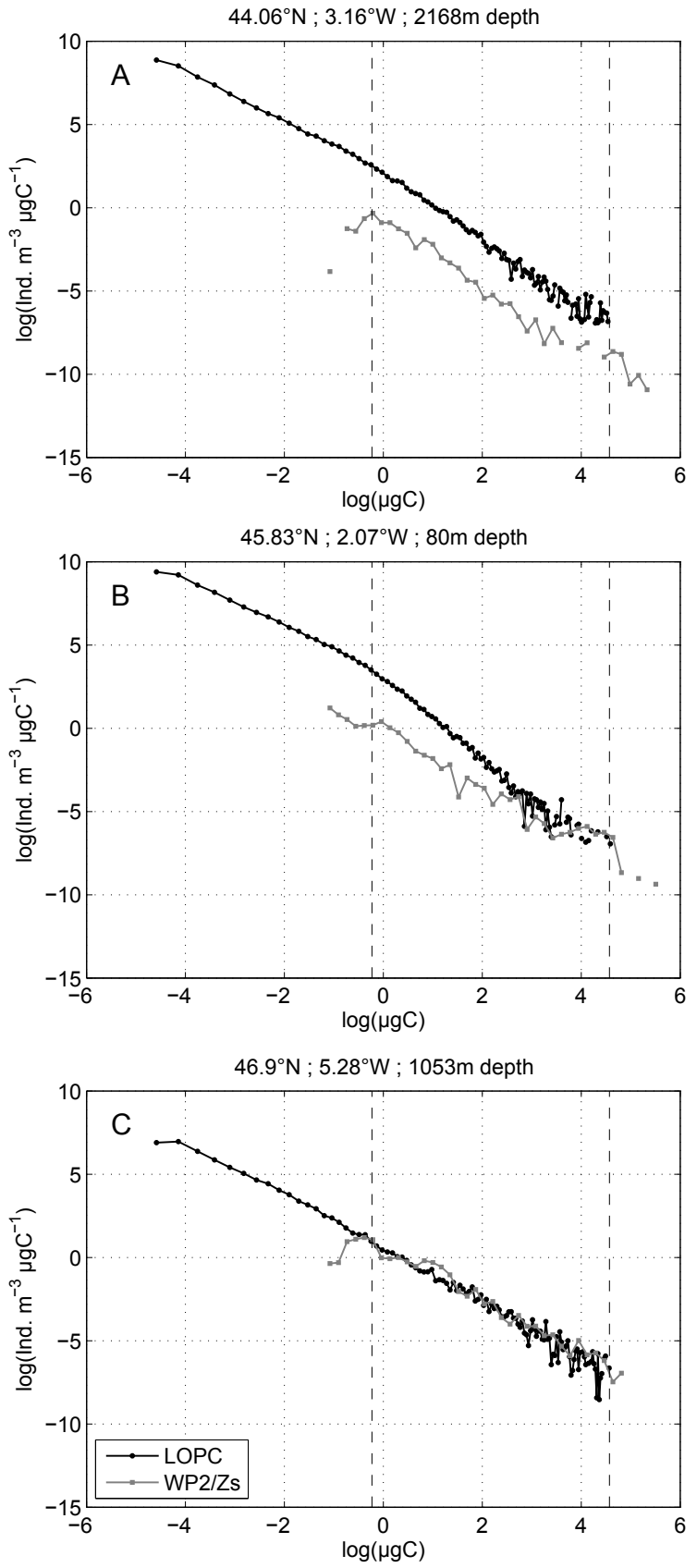

Figure 2. Examples of simultaneous number normalized size spectra (NNSS) measured by the LOPC (black lines) and by the WP2/Zs validated zooplankton (grey lines). The two vertical dashed lines indicate the limits of comparable size classes. Geographic coordinates and bottom depth are indicated. (a) shows an example where the LOPC overestimates the WP2/Zs for all size classes, (b) where the overestimation is only for smaller size classes and (c) where there is no visible overestimation.

slopes and intercepts, respectively. The overestimation of intercepts was also reduced with no significant difference between the means (Student $t$ test $p=0.31$ ).
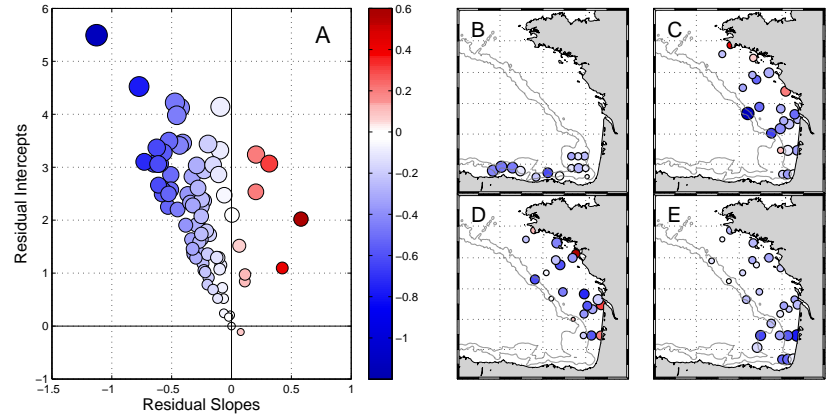

Figure 3. Size structure characteristics of residuals between NBSS estimated by the LOPC and by the WP2/Zs procedure. The color map indicates the value of the slope of the residuals (blue for negative slope, red for positive ones and white for null slopes). The size of points indicates the value of the intercept of residuals (the bigger the points, the larger the intercepts). (a) shows the relation between the slope and the intercept of residuals. (b-e) show the spatial distribution of residuals for the four cruises in which data are available for both LOPC and WP2/Zs (b: PELACUS 2007, c: PELGAS 2009, d: PELGAS 2010 and e: PELGAS 2011) using the same color map but size of points being divided by three for clarity.

Correlations between slopes and intercepts for WP2/Zs, LOPC and corrected LOPC are shown in Fig. 6. WP2/Zs slopes $(s)$ and intercepts $(a)$ are significantly correlated (Pearson $r=-0.86, p<0.001$ ) and related by a linear fit on the form $a=p_{1} s+p_{2}$, where $p_{1}=-2.568(-2.895$, $-2.241)$ and $p 2=-2.062(-2.372,-1.752)$, numbers in parentheses indicating the $95 \%$ confidence interval. For the LOPC, the Pearson correlation is of $-0.70(p<0.001)$ and the linear fit has coefficients $p_{1}=-4.144(-4.445,-3.842)$ and $p 2=-2.251(-2.551,-1.951)$. Slopes and intercepts of corrected LOPC size spectra are also significantly correlated (Pearson $r=-0.84, p<0.001$ ) and have the coefficients $p_{1}=-3.181(-3.331,-3.031)$ and $p_{2}=-2.606$ $(-2.727,-2.486)$, closer to those of the WP2/Zs.

\subsection{Spatial and interannual distribution of zooplankton}

On Fig. 6 the estimated biomass computed as the integral of a linear NBSS defined by its slope and intercept is displayed as a color scale in $\log _{10}$. The strength of the relation between biomass and size spectra parameters is affected by the position of the subset slopes vs. intercepts. For the values of slopes and intercepts observed here, there is a Pearson correlation of biomass and slopes of -0.51 $(p<0.001)$ and $\log _{10}(B)=-0.571 s+0.544$. The estimated zooplankton biomass concentrations range from 2.9 to $63.7 \mathrm{mgC} \mathrm{m}^{-3}$ with a mean of $11.4 \pm 8.2 \mathrm{mgC} \mathrm{m}^{-3}$ (median of $8.9 \mathrm{mgC} \mathrm{m}^{-3}$ ). A general tendency of large biomass associated with steeper size spectra is observed. Steep size spectra are mostly observed along the coasts, especially in the Gironde plume area and off Galicia, whereas the flattest size 
Table 3. Simplified results of the stepwise RDA performed with additional fractionated chlorophyll $a$ (three fractions) from PELGAS 2009, 2010 and 2011 (68 stations) showing only selected variables; skipped variables are indicated by “...”. Cum. Expl. shows the total cumulated variance explained by the stepwise RDA. Orig. Cum. Expl. shows the total variance explained by the stepwise RDA performed on the same subset of stations with the original set of variables (as in Table 2).

\begin{tabular}{lr}
\hline Variables & Cum. Exp. \\
\hline LOPC biomass & 0.41 \\
chl 3 & 0.51 \\
Bathymetry & 0.56 \\
chl 2 & 0.59 \\
Fluo. int. & 0.60 \\
$\ldots$ & \\
LOPC slope & 0.72 \\
chl 1 & 0.73 \\
$\ldots$ & \\
Cum. Expl. & 0.80 \\
\hline Orig. Cum. Expl. & 0.74 \\
\hline
\end{tabular}
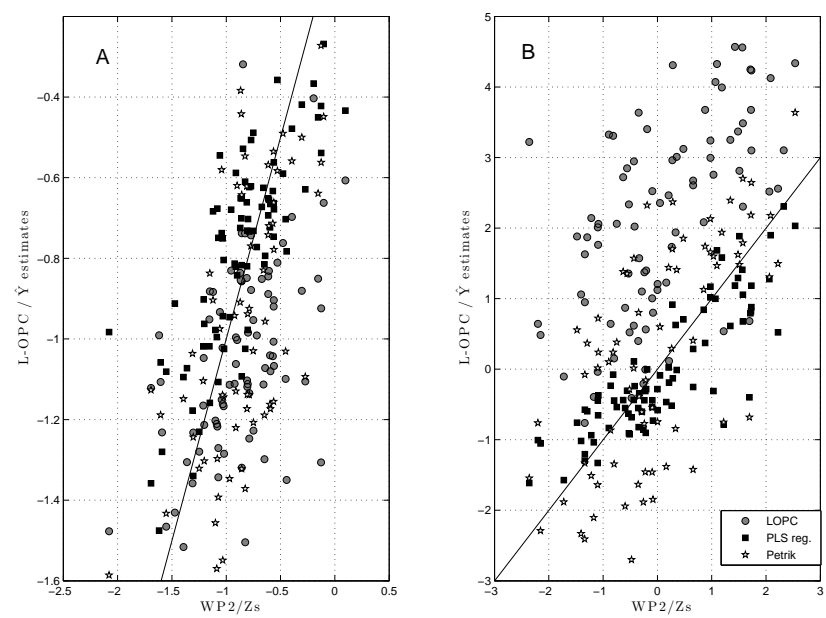

Figure 4. Scatter graph of the relations of NBSS slopes (a) and intercepts (b) estimated by the WP2/Zs vs. the raw LOPC (grey circles), and after the PLS (partial least square) regression was performed on the LOPC ( $\hat{Y}$, black plain square). In addition, the result of estimating NBSS parameters of LOPC data corrected using the method of Petrik et al. (2013) are added (grey stars). The $x=y$ line is added to each plot.

spectra are observed on the French continental shelf (Fig. 8). Furthermore, the productivity of zooplankton was calculated and ranged from 0.0011 to $0.58 \mathrm{mgC} \mathrm{m}^{-2} \mathrm{~d}^{-1}$, with a mean of $0.036 \pm 0.050$ and a median of $0.021 \mathrm{mgC} \mathrm{m}^{-2} \mathrm{~d}^{-1}$ Fig. 9 .

Interannual and spatial patterns were investigated through the 5 groups identified by the $K$ means clustering (Fig. 10). Annual and spatial distribution of these groups is shown in Fig. 11. The first group (blue circles, largest biomass concentration and steepest size spectra) is almost exclusively
Table 4. Same as Table 3 with zooplankton group abundances from PELGAS 2009, 2010 and 2011 as explanatory variables (total of 75 stations).

\begin{tabular}{lr}
\hline Variables & Cum. Exp. \\
\hline Acartia sp. & 0.49 \\
cladocerans & 0.66 \\
Calanus sp. & 0.76 \\
small calanoids & 0.82 \\
larvaceans & 0.87 \\
. & \\
Cum. Expl. & 0.92 \\
\hline Orig. Cum. Expl. & 0.71 \\
\hline
\end{tabular}
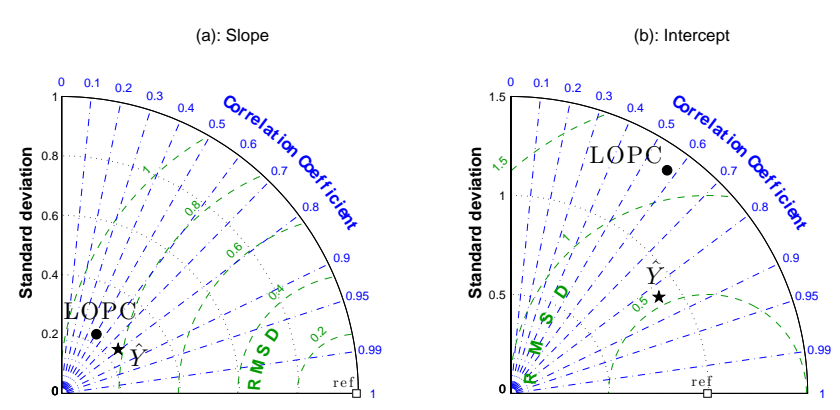

Figure 5. Taylor diagram (Taylor, 2001) of the correlation (R), the centered root mean square difference (RMSD) and standard deviation (STD) between NBSS parameters (a: slope and $\mathbf{b}$ : intercept) estimated by the WP2/Zs and estimated by the LOPC (black plain circles) and after the PLS (partial least square) regression performed on the LOPC $(\hat{Y}$, black plain stars). The white square indicates the $\operatorname{maximum}(R=1, \operatorname{RMSD}=0$ and $\mathrm{STD}=1)$.

found in the most coastal areas, notably in the main estuaries of the French coast. This group has an important interannual variability with low occurrences in 2011 compared to those of 2009 and 2010. The second group (green squares) occurs mainly in coastal areas, similar to group 1, although it extends farther over the shelf, and shows less interannual variability. The third group (red diamonds) is observed in 2005 and 2007 mainly on the Spanish and Portuguese coasts, while a northward extension is observed from 2009. The fourth group (black triangles, lowest biomass concentration and second flattest size spectra) is mainly observed at southern locations (Cantabrian Sea and Portuguese slope) in 2005, 2006 and 2007, and as for the third group, extends northward from 2009. The last group (pink stars, low biomass concentrations and flattest size spectra) is the most offshore. This group is also observed along the Spanish coast in 2007, close to the Gironde estuary in 2009 and 2010, and at some locations along the Brittany coast in 2012. 


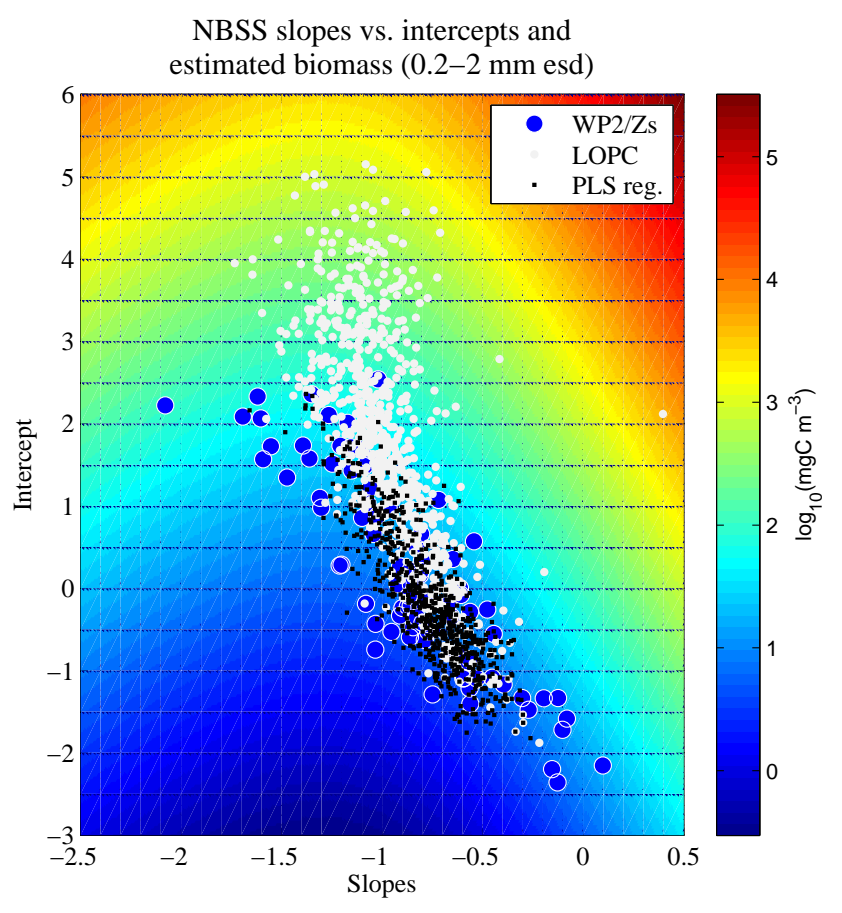

Figure 6. Scatter graph of the relations between slopes and intercepts computed from NBSS estimated by the WP2/Zs (blue circles), the LOPC (grey circles) and by the PLS (partial least square) regression (black square). The color map corresponds to the biomass computed as the integration of the log-linear NBSS in the range $0.2-2 \mathrm{~mm}$ ESD.

\section{Discussion}

\subsection{Correction of the size spectra}

The correction of the LOPC significantly improved its reliability as a measure of zooplankton size distribution, both in its correlation with the WP2/Zs (Fig. 5), and in the shape of the dependency between slopes and intercepts (Fig. 6). The proposed correction methodology makes the best use of available environmental information, both in situ and satellite, and also of the size distribution of all particles (LOPC). The LOPC NBSS parameters (total biomass and slope) appear to explain a large part of the variance of the non-living particles size distribution (Tables 2 and 3); the total explained variance decrease to $47 \%$ without them. This highlights the need to perform a minimum of basic in situ size measurements to estimate the size distribution of non-living particles, and ultimately, zooplankton.

In addition to the uncorrected LOPC NBSS properties, chlorophyll $a$ (either from satellite; Table 2, or as fractionated measurements; Table 3) appears as the second explanatory variable. It confirms that the majority of the difference between both instruments is due to particulate organic matter, being the highest in areas with detrital products of large phytoplankton blooms (fractions higher than $30 \mu \mathrm{m}$ ) or

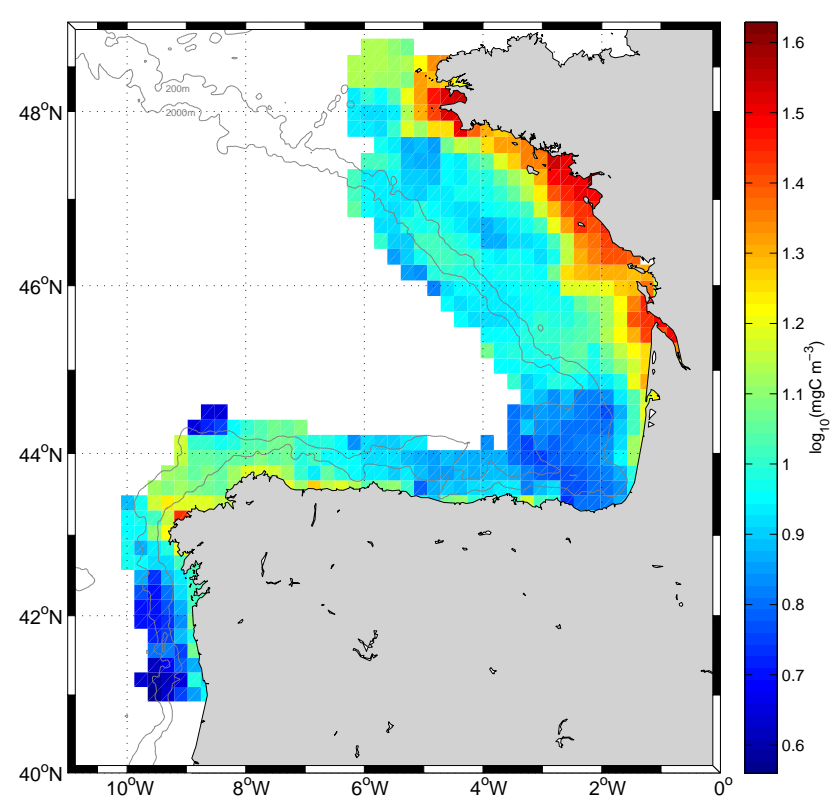

Figure 7. Spatial distribution of NBSS biomass concentration (in $\log _{10} \mathrm{mg} \mathrm{C} \mathrm{m}^{-3}$ ) estimated by the PLS (partial least square) from the surface to a maximum of $100 \mathrm{~m}$ depth.

associated zooplankton blooms (Guidi et al., 2009). Looking only at satellite-derived chlorophyll $a$, the highest variability is explained by values measured one week before (4.47\%), again highlighting the potential role of past bloom in detritus concentration, even if in the stepwise RDA the current chlorophyll $a$ situation takes priority. In opposition, inorganic SPM from satellite does not explain much variability due to their small size being unavailable in both type of measurements. The absence of a flow meter on WP2 net, however, does not allow doe the complete exclusion of an impact of clogging in rich water (the median chlorophyll $a$ encountered was of $0.90 \mu \mathrm{g} \mathrm{L}^{-1}$ with a maximum value of $\left.10.36 \mu \mathrm{g} \mathrm{L}^{-1}\right)$, thus potentially creating an artificial dependency with chlorophyll $a$. Yet, such clogging seems unlikely according to the characteristics of the plankton net used, with a filtering: mouth areas ratio adjusted to porosity and filtering volume, which is above the recommended ratio for coastal (or green) waters (Smith et al., 1968; Hernroth, 1987; Keen, 2013) and because high chlorophyll $a$ concentrations are located in shallow waters where towed duration is limited.

Julian day, taken separately, explains more than $10 \%$ of the variability. This may also be explained by the timing of sampling with respect to bloom phenology, with highest detritus concentrations in post-bloom conditions occurring later in spring (Steinberg et al., 2001). Non-living particulate material may, in addition, have terrestrial or resuspension origins, which would be reflected in the salinity, depth or distance to coast covariables; however, redundancy with other 


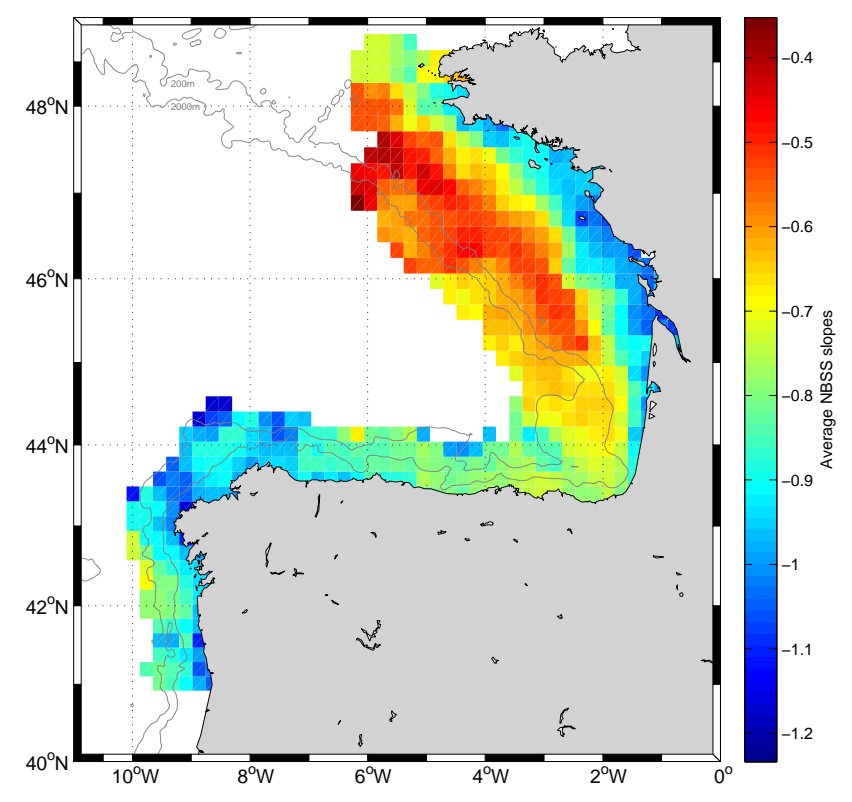

Figure 8. Spatial distribution of NBSS slopes estimated by the PLS (partial least square) regression.

variables may have prevented them from being at the top of the list of the cumulated explained variance.

Remaining unexplained variability may have several of the following origins, making further assessment from our study difficult: (i) insufficient information from the explanatory environmental variables and related measurement errors; (ii) errors in the estimation of volume sampled by the net (Nogueira et al., 2004; González-Quirós and Checkley, 2006; Schultes and Lopes, 2009), as well as further fractioning before ZooScan processing; (iii) varying efficiencies between instruments, especially at the tails of the size range, even if caution was taken in its selection, with potential avoidance of larger individuals.

Interestingly, the use of taxonomy information explained a larger part of the variance of non-living particles size distribution, revealing a strong influence, or correlation, of the zooplankton composition. This reveals also that taxonomy introduces spatial information such as distance from coast with community structuration along a coastal-offshore gradient (Albaina and Irigoien, 2004), timing information with species succession based on their phenology (see Valdés et al., 2007), and consequently some information on quantity and quality of associated detrital matter. In the case of fragile gelatinous zooplankton accounting for the difference between the two instrument measurements, the taxonomical information may also bring forth some information on the community assemblages unexplained by other covariables. However, this latter analysis with taxonomy was mainly exploratory since no simultaneous information is available for systematic correction. This also motivates further effort on

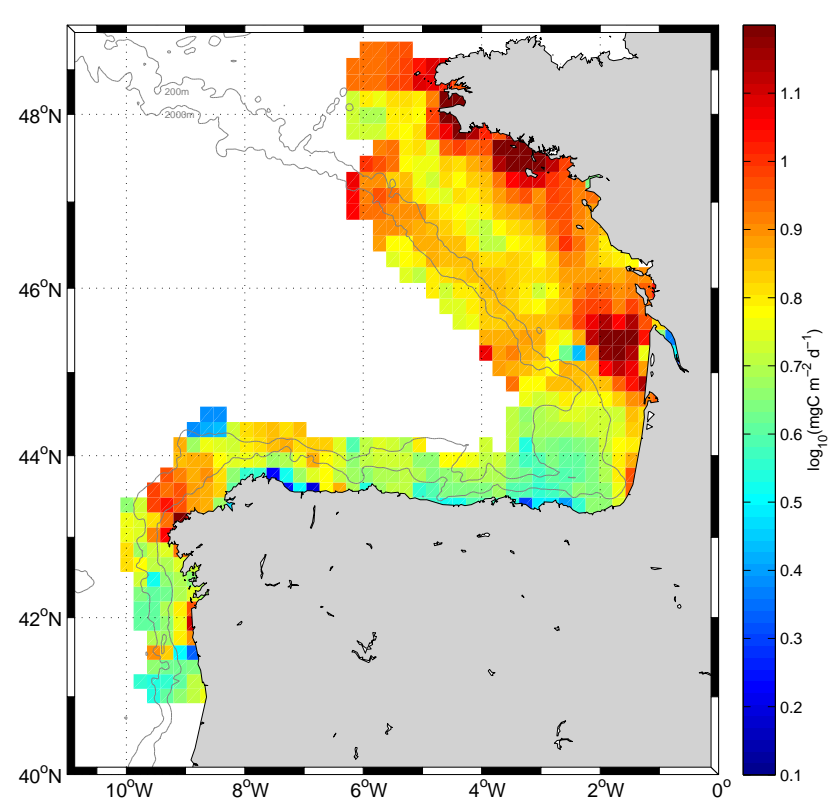

Figure 9. Spatial distribution of zooplankton productivity (in $\log _{10} \mathrm{mgC} \mathrm{m}^{-2} \mathrm{~d}^{-1}$ ) estimated by the PLS (partial least square) integrated from the surface to a maximum of $100 \mathrm{~m}$ depth.

the development of in situ imaging systems and on the measurements of zooplankton groups.

Using an independent method (Petrik et al., 2013) to estimate the size distribution of zooplankton tends to validate the present conclusions. The Petrik et al. (2013) method focuses on estimating the size distribution of non-living particles and the total volume they represent. By removing the estimated non-living particles from LOPC counts, this method can then be used to estimate the distribution of zooplankton, despite not being the primary focus of the initial study. The Petrik's estimated zooplankton NBSS parameters show a better correlation with WP2/Zs than those from the uncorrected LOPC. Moreover, NBSS intercepts are no longer significantly overestimated (Fig. 4). Although the method is different, the estimation of non-living particles size distribution is based solely on LOPC total counts. From the present analysis, it is observed that LOPC parameters only explain about $40 \%$ of the total variance, supporting the results obtained through the Petrik et al. (2013) methodology. The total particles size distribution may explain a large part of the variance; however, for a more accurate estimation, it may be necessary to take other parameters into consideration. Yet a subset of stations where both LOPC and zooplankton size spectra data are available is necessary to apply the method presented here, which is not the case in Petrik et al. (2013) where only LOPC data are needed. 


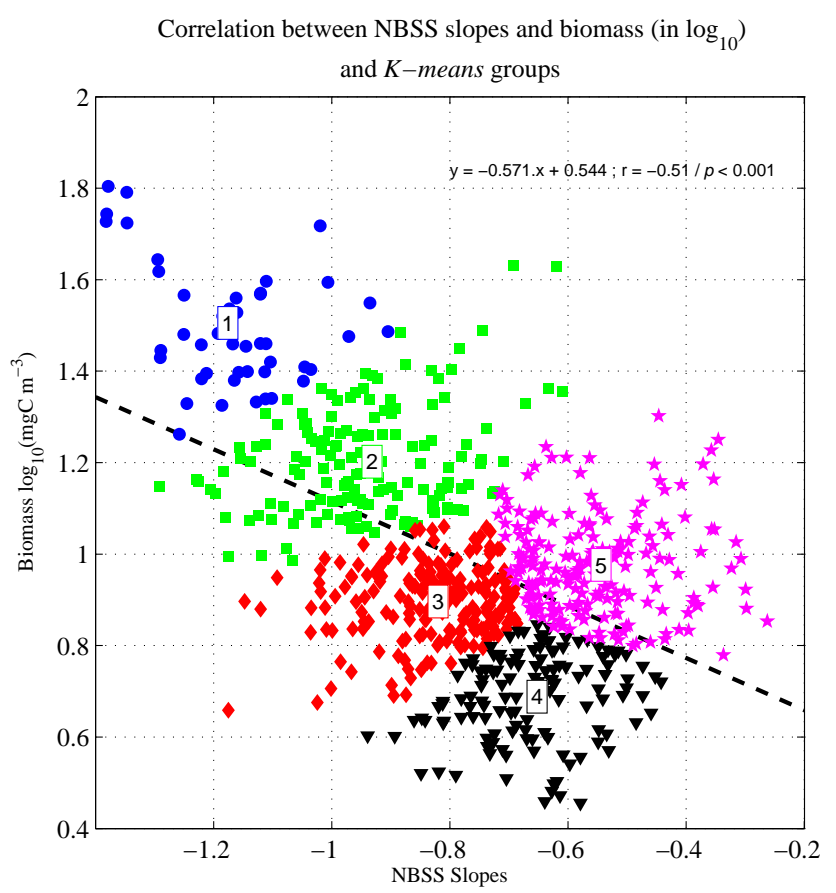

Figure 10. Correlation between slopes and the biomass computed as the integration of the log-linear NBSS in the range of $0.2-2 \mathrm{~mm}$ ESD. The correlation (Pearson) is significant with a $r=-0.51$. Result of five groups of $K$ means clustering based on estimated slope and biomass is shown with different colors and shapes. Group 1: blue circles, group 2: green squares, group 3: red diamonds, group 4: black triangles and group 5: pink stars.

\subsection{Size spectrum patterns}

The estimated mesozooplankton biomass $(2.9$ to $\left.63.7 \mathrm{mgC} \mathrm{m}^{-3}\right)$ is in agreement with values reviewed by Poulet et al. (1996) in the area, or with high-resolution sampling in spring over the southern shelf of the Bay of Biscay by Irigoien et al. (2009). The slopes of the NBSS range from -1.4 to -0.2 , with a mean of -0.8 , which is slightly flatter than the commonly accepted slope of -1 (or -1.22 when expressed in carbon units; Quiñones et al., 2003), typical of steady-state large ecosystems (Platt and Denman, 1977; Kerr and Dickie, 2001). This indicates a small : large ratio in favor of larger individuals, most likely explained by the post-bloom conditions; larger zooplankton species often observed later in spring than smaller ones (e.g., Valdés et al., 2007; Vandromme et al., 2011, for the Bay of Biscay and Ligurian Sea respectively). Average spatial distribution of size structure confirms the remarkable positive coastal to offshore gradient of the NBSS slope, with a slight decrease when reaching the shelf break, especially over the French shelf in coherence with observations by Sourisseau and Carlotti (2006) and Irigoien et al. (2009). An opposite gradient over the north Iberian shelf is not observed, as clearly emerged from observations by Nogueira

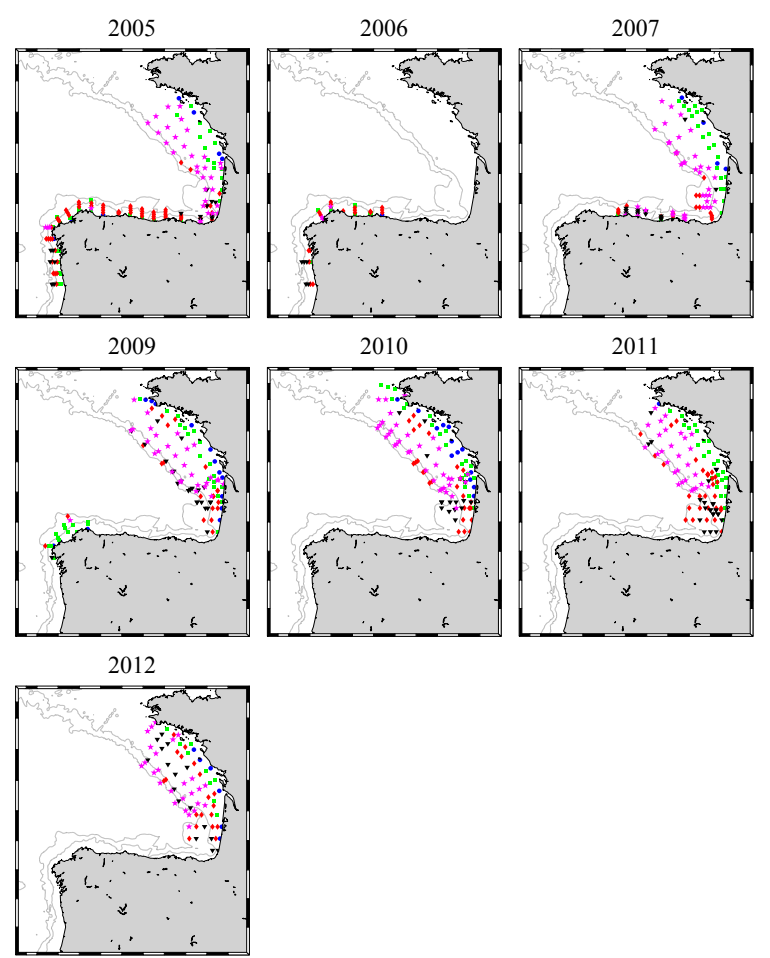

Figure 11. Spatial and interannual distribution of $K$ means groups as established in Fig. 10 for the 7 years. Groups are represented by the same colors and shapes as in Fig. 10

et al. (2004) during the 2002 winter-spring transition, but the west to east trend of steeper to flatter slopes is observed. In any case, the few number of years of available data in the build of a robust climatology in that area should be noted.

From 5-year-long high-resolution sampling over a transect offshore the Gironde estuary, Albaina and Irigoien (2004) described the following structuration for the mesozooplankton community: (i) a river plume area with high abundance of small individuals; (ii) a shelf break frontal zone with relatively high abundance; (iii) the shelf zone with much lower abundance but relative predominance of large-sized species; (iv) an oceanic zone. Apart from the fact that the latter that is not well sampled in our surveys, except in 2011 and 2012 in the south (Fig. 11), results of the present study show a similar cross-shelf structure over the whole north of the Gironde area. Indeed, the coastal zone shows steeper slopes with a large proportion of small individuals, the mid-shelf zone has the flattest slopes with the highest relative proportion of large individuals, and with the slope steepening over the shelf break. Such a coastal to offshore gradient was also observed by Marcolin et al. (2013) in the Abrolhos Bank ecosystem (SE Atlantic) with flatter slopes at oceanic stations associated to a greater contribution of larger organisms and less productive ecosystems. As highlighted by Marcolin et al. (2013) the association between steeper NBSS slopes and productive systems depends on the size range considered. Steeper 
NBSS associated to less productive systems are observed in studies working on a smaller size range (e.g., $>1 \mu \mathrm{m}$ ESD; Iriarte and González, 2004; San Martin et al., 2006), while steeper NBSS associated to productive systems are observed when the sizes considered to construct the NBSS are generally larger than $250 \mu \mathrm{m}$ ESD (Zhou et al., 2009; Basedow et al., 2010; Marcolin et al., 2013, this study). In less productive systems a significant proportion of the primary productivity is provided by microbial food webs (Iriarte and González, 2004) and the smaller fraction of phytoplankton (Guidi et al., 2009), therefore leading to steeper NBSS in the size range $>1$ to $\approx 200 \mu \mathrm{m}$ ESD. However, on the mesozooplankton size range, high productivity leads to a higher proportion of herbivores, generally smaller than carnivores, resulting in steeper NBSS (Zhou, 2006; Zhou et al., 2009).

Despite this size spectrum gradient, the biomass, when vertically integrated, is relatively homogeneous, as also observed by Albaina and Irigoien (2004), with only a slight decrease in the mid-shelf area and an increase of biomass along the coastal strip north of the Gironde, up to Brittany. The bigger size of individuals in the mid-shelf area observed in this study may compensate for the lower abundance. The absence of a clear pattern in cross-shelf structuration in the south of the Bay of Biscay and over the Iberian shelf is certainly due to the absence of the mid-shelf habitat (low occurrence of group 5, see Fig. 11, except 2005 and 2007) with a tightened and continuous transition between coastal and shelf break habitats (Albaina and Irigoien, 2007; Stenseth et al., 2006). Large continental inputs along the coast and internal wave breakdown (Pingree et al., 1981) over the continental slope are strong and regular drivers of the ecosystem dynamics over the French northern shelf. Those processes are lacking and replaced by more variable processes such as the influence of the Iberian slope current or upwelling events over the Iberian shelf (Llope et al., 2006), which consequently shows a higher spatio-temporal variability over the years.

\subsection{Productivity and trophic control}

The integrated mesozooplankton productivity (Fig. 9) gives a significantly different picture than the biomass (Fig. 7). The high biomass areas such as along the French and Galician coasts still appear highly productive, but in addition, the shelf break is also more productive when compared to the midshelf, which is more conspicuous again over the French shelf. This is partly due to bathymetry, which tends to lower the values in coastal areas after vertical integration as compared to offshore deeper waters, but is also explained by differences in size structure of the zooplankton and underlying primary production (Marquis et al., 2011). The mid-shelf, with the flattest slopes and relatively large zooplankton, is estimated as less productive, even if the biomass seems close to the one over the slope. This region is often rapidly and strongly stratified in spring (Koutsikopoulos et al., 1996) with relatively low new primary production limited to the thermocline after the spring bloom, and has water masses with long residence time under low residual circulation (Charria et al., 2013). In opposition, productive coastal areas are continuously under the influence of rich river inputs (i.e., Loire and Gironde plumes), tidal fronts, and benthic remineralization, and the productive frontal structure of the continental slope regularly receives nutrient inputs from breakdown of internal tides; this pattern strongly emerges in the geographic distribution of zooplankton productivity (Fig. 9).

At the scale of our defined habitats, the slope of zooplankton NBSS is the result of local structuration of the community, which gives information on matter transfer efficiency across trophic levels and on types of trophic control (Suthers et al., 2006). From a literature review, Daewel et al. (2014) did not find evidence of top-down control on zooplankton at the scale of the Bay of Biscay, yet it may occur at local scale for particular seasons. Within the size range of mesozooplankton (0.2-2 mm ESD), steeper slopes are generally related to lower efficiency of the matter flux, potentially with top-down control and a fewer number of trophic levels, whereas flatter slope areas are associated with efficient transfer under bottom-up control and a higher number of trophic levels (Zhou, 2006; Basedow et al., 2010; Marcolin et al., 2013). So, even if more productive, coastal areas (especially plumes) and to a lesser extent shelf break habitats may have a low transfer efficiency, mid-shelf areas may have a high transfer efficiency, through the structuration of the planktonic food web (Marquis et al., 2011). The fact that similar ranges of biomass occur in the mid-shelf and over the slope, despite higher productivity over the slope, is potentially a sign of higher efficiency for the mid-shelf habitat. There are usually low fish occurrences in this habitat in spring during the small pelagic survey (e.g., Petitgas et al., 2011, for anchovy), which has the possible effect of releasing top-down control on large zooplankton. In opposition, the southeastern Bay of Biscay has high fish occurrence (Petitgas et al., 2011), which may explain the lower biomass observed there than in the north, due to possible top-down control.

\section{Conclusions}

The LOPC has been operating in the Bay of Biscay since 2005, during Spanish and French small pelagic surveys. Considering that fewer stations are sampled with net due to time constraints, and the considerable amount of lab work for taxon identification and/or size measurements, which often prevents complete analysis of the full set of sampled stations, the LOPC combined with our methodology provides a robust and rapid access to key information on the size structure of the mesozooplankton ( 400-2000 $\mu \mathrm{m}$ ESD, in this study). Selected samples may then be further analyzed with binocular or image analysis.

During springtime in the Bay of Biscay, the high productive areas were associated with steeper NBSS, higher 
biomass and potentially low trophic transfer efficiency. Lesser productive areas were associated with flatter NBSS, less biomass and potentially higher trophic transfer efficiency. These observations follow a general trend of mesozooplankton NBSS parameters relationships with ecosystems productivity observed at other locations (e.g., Zhou et al., 2009; Basedow et al., 2010; Marcolin et al., 2013). Yet, a high variability in this trend was observed at the regional scale of the Bay of Biscay associated mostly with hydrological and geographical features.

Combining biomass from biogeochemical model results and size spectrum observations is an investigated approach to estimate the available fraction of the total biomass to upper trophic levels (Daewel et al., 2014). The significant but relatively weak correlation between slope and biomass (Fig. 6) obtained over the whole domain does not permit a direct estimation of this fraction from only model biomass. Alternatively, combining model results and our NBSS slope climatology can provide a first estimation. Temporal stability of the maps of size structure presented in this study has to be verified before this approach is generalized for estimation over the whole year.

Even if it is able to provide abundance and biomass on lower size classes with more efficiency than the WP2 mounted with a mesh of $200 \mu \mathrm{m}$, the LOPC is not efficient for the microplankton size classes, also key in the energy transfer to upper trophic level, in particular as food for fish larvae (Morote et al., 2010; Yañez Rubio et al., 2011). Nogueira et al. (2004) showed some continuity between the size spectra obtained from a $20 \mu \mathrm{m}$ net and an in situ OPC. However, this has to be verified over a larger set of stations before any extrapolation can be proposed from the LOPC-derived size spectra. Some in situ instruments (e.g., the LISST, Mikkelsen et al., 2005) or instrument directly operational on-board from (e.g., the FlowCAM, Sieracki et al., 1998), may quickly provide key additional information.

Acknowledgements. We are grateful to the R/V Thalassa crew, and to J. Massé for coordinating the PELGAS surveys over the last decade. We also thank B. Planque for initiating the use of the LOPC on PELGAS survey, and to E. Antajan for helping us with the use of the ZooScan. We also want to greatly thank Frédéric Ibañez who introduced some of us to the world of statistics and sadly passed away recently. P. Vandromme fellowship was founded by the project REPROdUCE of the ERA-NET MARIFISH (Contract ERAC, CT-2006-025989) and french National Research Agency (ANR). The SEAMAN project of the EU FP7 ERA-NET SEASERA completed the funding. The constructive and helpful reviews of E. Bachiller and S. Basedow greatly improved the manuscript.

The service charges for this open access publication have been covered by a Research Centre of the Helmholtz Association.

Edited by: M. Hoppema

\section{References}

Albaina, A. and Irigoien, X.: Relationships between frontal structures and zooplankton communities along a cross-shelf transect in the Bay of Biscay (1995 to 2003), Mar. Ecol.-Prog. Ser., 284, 65-75, doi:10.3354/meps284065, 2004.

Albaina, A. and Irigoien, X.: Fine scale zooplankton distribution in the Bay of Biscay in spring 2004, J. Plankton Res., 29, 851-870, doi:10.1093/plankt/fbm064, 2007.

Bachiller, E. and Irigoien, X.: Allometric relations and consequences for feeding in small pelagic fish in the Bay of Biscay, ICES J. Mar. Sci., 70, 232-243, doi:10.1093/icesjms/fss171, 2013.

Bachiller, E., Fernandes, J. A., and Irigoien, X.: Improving semiautomated zooplankton classification using an internal control and different imaging devices, Limnol. Oceanogr.-Meth., 10, 19, doi:10.4319/lom.2012.10.1, 2012.

Baird, M. E. and Suthers, I. M.: A size-resolved pelagic ecosystem model, Ecol. Model., 203, 185-203, doi:10.1016/j.ecolmodel.2006.11.025, 2007.

Barnes, C., Irigoien, X., De Oliveira, J. A. A., Maxwell, D., and Jennings, S.: Predicting marine phytoplankton community size structure from empirical relationships with remotely sensed variables, J. Plankton Res., 33, 13-24, doi:10.1093/plankt/fbq088, 2011.

Basedow, S. L., Tande, K. S., and Zhou, M.: Biovolume spectrum theories applied: spatial patterns of trophic levels within a mesozooplankton community at the polar front, J. Plankton Res., 32, 1105-1119, doi:10.1093/plankt/fbp110, 2010.

Basedow, S. L., Tande, K. S., Norrbin, M. F., and Kristiansen, S. A.: Capturing quantitative zooplankton information in the sea: Performance test of laser optical plankton counter and video plankton recorder in a Calanus finmarchicus dominated summer situation, Prog. Oceanogr., 108, 72-80, doi:10.1016/j.pocean.2012.10.005, 2013.

Blanco, J., Echevarría, F., and Garcia, C. M.: Dealing with sizespectra: some conceptual and mathematical problems, Sci. Mar. 58, 17-29, 1994.

Charria, G., Lazure, P., Le Cann, B., Serpette, A., Reverdin, G., Louazel, S., Batifoulier, F., Dumas, F., Pichon, A., and Morel, Y.: Surface layer circulation derived from Lagrangian drifters in the Bay of Biscay, J. Marine Syst., 109-110, S60-S76, doi:10.1016/j.jmarsys.2011.09.015, 2013.

Checkley, Jr. D., Davis, R., Herman, A., Jackson, G., Beanlands, B., and Regier, L.: Assessing plankton and other particles in situ with the SOLOPC, Limnol. Oceanogr., 53, 2123-2136, doi:10.4319/lo.2008.53.5_part_2.2123, 2008 .

Daewel, U., Peck, M. A., Kühn, W., St. John, M. A., Alekseeva, I., and Schrum, C.: Coupling ecosystem and individualbased models to simulate the influence of environmental variability on potential growth and survival of larval sprat (Sprattus sprattus L.) in the North Sea, Fish. Oceanogr., 17, 333-351, doi:10.1111/j.1365-2419.2008.00482.x, 2008.

Daewel, U., Hjollo, S. S., Huret, M., Ji, R., Maar, M., Niiranen, S., Travers-Trolet, M., Peck, M. A., and van de Wolfshaar, K. E.: Predation control of zooplankton dynamics: a review of observations and models, ICES J. Mar. Sci., 71, 254-271, doi:10.1093/icesjms/fst125, 2014. 
de Jong, S.: SIMPLS: an alternative approach to partial least squares regression, Chemometr. Intell. Lab., 18, 251-263, doi:10.1016/0169-7439(93)85002-X, 1993.

Doray, M., Badts, V., Masse, J., Duhamel, E., Huret, M., Doremus, G., and Petitgas, P.: Manual of fisheries survey protocols. PELGAS surveys (PELagiques GAScogne), Ifremer, doi:10.13155/30259, 2014.

Gaardsted, F., Tande, K. S., and Basedow, S. L.: Measuring copepod abundance in deep-water winter habitats in the NE Norwegian Sea: intercomparison of results from laser optical plankton counter and multinet, Fish. Oceanogr., 19, 480-492, doi:10.1111/j.1365-2419.2010.00558.x, 2010.

Gohin, F., Loyer, S., Lunven, M., Labry, C., Froidefond, J., Delmas, D., Huret, M., and Herbland, A.: Satellite-derived parameters for biological modelling in coastal waters: illustration over the eastern continental shelf of the Bay of Biscay, Remote Sens. Environ., 95, 29-46, doi:10.1016/j.rse.2004.11.007, 2005.

Gómez-Canchong, P., Blanco, J. M., and Quiñones, R. A.: On the use of biomass size spectra linear adjustments to design ecosystem indicators, Sci. Mar., 77, 257-268, doi:10.3989/scimar.03708.22A, 2013.

González-Quirós, R. and Checkley, D. M.: Occurrence of fragile particles inferred from optical plankton counters used in situ and to analyze net samples collected simultaneously, J. Geophys. Res., 111, C05S06, doi:10.1029/2005JC003084, 2006.

Gorsky, G., Ohman, M. D., Picheral, M., Gasparini, S., Stemmann, L., Romagnan, J.-B., Cawood, A., Pesant, S., GarciaComas, C., and Prejger, F.: Digital zooplankton image analysis using the ZooScan integrated system, J. Plankton Res., 32, 285303, doi:10.1093/plankt/fbp124, 2010.

Guidi, L., Stemmann, L., Jackson, G. a., Ibanez, F., Claustre, H., Legendre, L., Picheral, M., and Gorsky, G.: Effects of phytoplankton community on production, size and export of large aggregates: A world-ocean analysis, Limnol. Oceanogr., 54, 19511963, doi:10.4319/lo.2009.54.6.1951, 2009.

Herman, A. W. W., Beanlands, B., and Phillips, E. F. F.: The next generation of Optical Plankton Counter: the Laser-OPC, J. Plankton Res., 26, 1135-1145, doi:10.1093/plankt/fbh095, 2004.

Hernroth, L.: Sampling and filtration efficiency of two commonly used plankton nets. A comparative study of the Nansen net and the Unesco WP 2 net, J. Plankton Res., 9, 719-728, doi:10.1093/plankt/9.4.719, 1987.

Hirst, A. G. and Bunker, A. J.: Growth of marine planktonic copepods: global rates and patterns in relation to chlorophyll $a$, temperature, and body weight, Limnol. Oceanogr., 48, 1988-2010, doi:10.4319/lo.2003.48.5.1988, 2003.

Huntley, M. and Boyd, C.: Food-limited growth of marine zooplankton, Am. Nat., 124, 455-478, doi:10.1086/284288, 1984.

Iriarte, J. and González, H.: Phytoplankton size structure during and after the 1997/98 El Niño in a coastal upwelling area of the northern Humboldt Current System, Mar. Ecol.-Prog. Ser., 269, 8390, doi:10.3354/meps269083, 2004.

Irigoien, X., Fernandes, J. A., Grosjean, P., Denis, K., Albaina, A., and Santos, M.: Spring zooplankton distribution in the Bay of Biscay from 1998 to 2006 in relation with anchovy recruitment, J. Plankton Res., 31, 1-17, doi:10.1093/plankt/fbn096, 2009.

Kara, A. B., Rochford, P. A., and Hurlburt, H. E.: An optimal definition for ocean mixed layer depth, J. Geophys. Res.-Oceans, 105, 16803-16821, doi:10.1029/2000JC900072, 2000.
Keen, E.: A practical designer's guide to mesozooplankton nets, available at (last access: 15 October 2014): http://acsweb.ucsd.edu/ ekeen/resources/Choosing-a-Net.pdf, 2013.

Kerr, S. R. and Dickie, L. M.: The Biomass Spectrum: A PredatorPrey Theory of Aquatic Production, Columbia University Press, 2001.

Koutsikopoulos, C., Le Cann, B., and Cann, B. L. E.: Physical processes and hydrological structures related to the Bay of Biscay anchovy, Sci. Mar., 60, 9-19, 1996.

Krupica, K. L., Sprules, W. G., and Herman, A. W.: The utility of body size indices derived from optical plankton counter data for the characterization of marine zooplankton assemblages, Cont. Shelf. Res., 36, 29-40, doi:10.1016/j.csr.2012.01.008, 2012.

Legendre, P. and Legendre, L.: Numerical Ecology, 3rd Edn., Elsevier, Amsterdam, 2012.

Lehette, P. and Hernández-León, S.: Zooplankton biomass estimation from digitized images: a comparison between subtropical and Antarctic organisms, Limnol. Oceanogr.-Meth., 7, 304-308, doi:10.4319/lom.2009.7.304, 2009.

Llope, M., Anadón, R., Viesca, L., Quevedo, M., GonzálezQuirós, R., and Stenseth, N. C.: Hydrography of the southern Bay of Biscay shelf-break region: Integrating the multiscale physical variability over the period 1993-2003, J. Geophys. Res., 111, C09021, doi:10.1029/2005JC002963, 2006.

Marcolin, C. D. R., Schultes, S., Jackson, G. A., and Lopes, R. M.: Plankton and seston size spectra estimated by the LOPC and ZooScan in the Abrolhos Bank ecosystem (SE Atlantic), Cont. Shelf. Res., 70, 74-87, doi:10.1016/j.csr.2013.09.022, 2013.

Marquis, E., Niquil, N., Vezina, A. F., Petitgas, P., and Dupuy, C.: Influence of planktonic foodweb structure on a system's capacity to support pelagic production: an inverse analysis approach, ICES J. Mar. Sci., 68, 803-812, doi:10.1093/icesjms/fsr027, 2011.

Mauchline, J.: The biology of Calanoid Copepods, Adv. Mar. Biol., 33, 1-710, 1998.

Mikkelsen, O. A., Hill, P. S., Milligan, T. G., and Chant, R. J.: In situ particle size distributions and volume concentrations from a LISST-100 laser particle sizer and a digital floc camera, Cont. Shelf. Res., 25, 1959-1978, doi:10.1016/j.csr.2005.07.001, 2005.

Morote, E., Olivar, M. P., Villate, F., and Uriarte, I.: A comparison of anchovy (Engraulis encrasicolus) and sardine (Sardina pilchardus) larvae feeding in the Northwest Mediterranean: influence of prey availability and ontogeny, ICES J. Mar. Sci., 67, 897-908, doi:10.1093/icesjms/fsp302, 2010.

Nichols, J. H. and Thompson, A. B.: Mesh Selection of Copepodite and Nauplius Stages of 4 Calanoid Copepod Species, J. Plankton Res., 13, 661-671, 1991.

Nogueira, E., González-Nuevo, G., Bode, A., Varela, M., Morán, X. A. G., and Valdés, L.: Comparison of biomass and size spectra derived from optical plankton counter data and net samples: application to the assessment of mesoplankton distribution along the Northwest and North Iberian Shelf, ICES J. Mar. Sci., 61, 508-517, doi:10.1016/j.icesjms.2004.03.018, 2004.

Peters, R. H. and Wassenberg, K.: The Effect of body size on animal abundance, Oecologia, 60, 89-96, doi:10.1007/BF00379325, 1983. 
Petitgas, P., Doray, M., Masse, J., and Grellier, P.: Spatially explicit estimation of fish length histograms, with application to anchovy habitats in the Bay of Biscay, ICES J. Mar. Sci., 68, 2086-2095, doi:10.1093/icesjms/fsr139, 2011.

Petrik, C. M., Jackson, G. A., and Checkley, D. M.: Aggregates and their distributions determined from LOPC observations made using an autonomous profiling float, Deep-Sea Res. Pt. I, 74, 6481, doi:10.1016/j.dsr.2012.12.009, 2013.

Picheral, M., Guidi, L., Stemmann, L., Karl, D. M., Iddaoud, G., and Gorsky, G.: The underwater vision profiler 5: an advanced instrument for high spatial resolution studies of particle size spectra and zooplankton, Limnol. Oceanogr.-Meth., 8, 462-473, doi:10.4319/lom.2010.8.462, 2010.

Pingree, R. D., Mardell, G. T., and Cartwright, D. E.: Slope turbulence, internal waves and phytoplankton growth at the celtic sea shelf-break [and discussion], Philos. T. R. Soc. A, 302, 663-682, doi:10.1098/rsta.1981.0191, 1981.

Platt, T. and Denman, K.: Organization in Pelagic ecosystem, Helgoland. Wiss. Meer., 30, 575-581, 1977.

Poulet, S. A., Laabir, M., and Chaudron, Y.: Characteristic features of zooplankton in the Bay of Biscay, Sci. Mar., 60, 79-95, 1996.

Quiñones, R. A., Platt, T., and Rodríguez, J.: Patterns of biomasssize spectra from oligotrophic waters of the Northwest Atlantic, Progr. Oceanogr., 57, 405-427, doi:10.1016/S00796611(03)00108-3, 2003.

Rosipal, R., Kr, N., and Krämer, N.: Overview and recent advances in partial least squares, in: Subspace, Latent Structure and Feature Selection SE-2, edited by: Saunders, C., Grobelnik, M., Gunn, S., and Shawe-Taylor, J., Vol. 3940 of Lecture Notes in Computer Science, Springer Berlin Heidelberg, 34-51, doi:10.1007/11752790_2,2006.

San Martin, E., Irigoien, X., Harris, R. P., López-Urrutia, A., Zubkov, M. V., and Heywood, J. L.: Variation in the transfer of energy in marine plankton along a productivity gradient in the Atlantic Ocean, Limnol. Oceanogr., 51, 2084-2091, doi:10.4319/lo.2006.51.5.2084, 2006.

Schultes, S. and Lopes, R. M.: Laser optical plankton counter and zooscan intercomparison in tropical and subtropical marine ecosystems, Limnol. Oceanogr.-Meth., 7, 771-784, doi:10.4319/lom.2009.7.771, 2009.

Sheldon, R. W., Sutcliffe, W. H., and Prakash, A.: The size distribution of particles in the ocean, Limnol. Oceanogr., 17, 327-340, doi:10.4319/lo.1972.17.3.0327, 1972.

Sieracki, C. K., Sieracki, M. E., and Yentsch, C. S.: An imagingin-flow system for automated analysis of marine microplankton, Mar. Ecol.-Progr. Ser., 168, 285-296, 1998.

Smith, P. E., Counts, R. C., and Cutter, R. I.: Changes in filtering efficiency of plankton nets due to clogging under tow, J. Cons. int. Explor. Mer, 32(2), 232-248, 1968.

Sourisseau, M. and Carlotti, F.: Spatial distribution of zooplankton size spectra on the French continental shelf of the Bay of Biscay during spring 2000 and 2001, J. Geophys. Res., 111, p. 12, doi:10.1029/2005JC003063, 2006.

Steinberg, D. K., Carlson, C. A., Bates, N. R., Johnson, R. J., Michaels, A. F., and Knap, A. H.: Overview of the US JGOFS Bermuda Atlantic Time-series Study (BATS): a decade-scale look at ocean biology and biogeochemistry, Deep-Sea Res. Pt. II, 48, 1405-1447, doi:10.1016/S0967-0645(00)00148-X, 2001.
Stemmann, L. and Boss, E.: Plankton and particle size and packaging: from determining optical properties to driving the biological pump, Annual Review of Marine Science, 4, 263-290, doi:10.1146/annurev-marine-120710-100853, 2012.

Stenseth, N. C., Llope, M., Anadón, R., Ciannelli, L., Chan, K.S., Hjermann, D. O., Bagoien, E., and Ottersen, G.: Seasonal plankton dynamics along a cross-shelf gradient, Proc. Biol. Sci. R. Soc., 273, 2831-2838, doi:10.1098/rspb.2006.3658, 2006.

Suthers, L. M., Taggart, C. T., Rissik, D., Baird, M. E., and Suthers, I.: Day and night ichthyoplankton assemblages and zooplankton biomass size spectrum in a deep ocean island wake, Mar. Ecol.-Prog. Ser., 322, 225-238, doi:10.3354/meps322225, 2006.

Taylor, K. E.: Summarizing multiple aspects of model performance in a single diagram, J. Geophys. Res., 106, 7183, doi:10.1029/2000JD900719, 2001.

Valdés, L., López-Urrutia, A., Cabal, J., Alvarez-Ossorio, M., Bode, A., Miranda, A., Cabanas, M., Huskin, I., Anadón, R., Alvarez-Marqués, F., Llope, M., and Rodríguez, N.: A decade of sampling in the Bay of Biscay: what are the zooplankton time series telling us?, Prog. Oceanogr., 74, 98-114, doi:10.1016/j.pocean.2007.04.016, 2007.

Vandromme, P., Stemmann, L., Berline, L., Gasparini, S., Mousseau, L., Prejger, F., Passafiume, O., Guarini, J.-M., and Gorsky, G.: Inter-annual fluctuations of zooplankton communities in the Bay of Villefranche-sur-mer from 1995 to 2005 (Northern Ligurian Sea, France), Biogeosciences, 8, 3143-3158, doi:10.5194/bg-8-3143-2011, 2011.

Vandromme, P., Stemmann, L., Garcìa-Comas, C., Berline, L., Sun, X., Gorsky, G., Garcia-Comas, C., Colbert, S., Picheral, M., Gasparini, S., Guarini, J.-M., and Prejger, F.: Assessing biases in computing size spectra of automatically classified zooplankton from imaging systems: a case study with the ZooScan integrated system, Methods in Oceanography, 1-2, 321, doi:10.1016/j.mio.2012.06.001, 2012.

Ward, B. A., Dutkiewicz, S., Jahn, O., and Follows, M. J.: A size-structured food-web model for the global ocean, Limnol. Oceanogr., 57, 1877-1891, doi:10.4319/1o.2012.57.6.1877, 2012.

Woodd-Walker, R. S., Gallienne, C. P., and Robins, D. B.: A test model for optical plankton counter (OPC) coincidence and a comparison of OPC-derived and conventional measures of plankton abundance, J. Plankton Res., 22, 473-483, doi:10.1093/plankt/22.3.473, 2000.

Yañez Rubio, A., Llanos-Rivera, A., Castro, L., Claramunt, G., and Herrera, L.: Variations in type, width, volume and carbon content of anchoveta Engraulis ringens food items during the early larval stages, J. Mar. Biol. Assoc. UK, 91, 1207-1213, doi:10.1017/S0025315410001748, 2011.

Zhou, M.: What determines the slope of a plankton biomass spectrum?, J. Plankt. Res., 28, 437-448, doi:10.1093/plankt/fbi119, 2006.

Zhou, M., Tande, K. S., Zhu, Y. W., and Basedow, S.: Productivity, trophic levels and size spectra of zooplankton in northern Norwegian shelf regions, Deep-Sea Res. Pt. II, 56, 1934-1944, doi:10.1016/j.dsr2.2008.11.018, 2009.

Zhou, M., Carlotti, F., and Zhu, Y.: A size-spectrum zooplankton closure model for ecosystem modelling, J. Plankton Res., 32, 1147-1165, doi:10.1093/plankt/fbq054, 2010. 